\title{
A FormaÇão EM CiênCIA da INFORMAÇão na FranÇa, no CANAdÁ E na DINAMARCA: COMPARAÇÃO COM O SISTEMA BRASILEIRO ${ }^{1}$
}

\author{
MIRIAM VIEIRA DA CUNHA - E-mail: mcunha@unetsul.com.br \\ Professora do Departamento de Ciência da Informação \\ Universidade Federal de Santa Catarina
}

\begin{abstract}
RESUMO
Apresenta o sistema de formação em Ciência da Informação na França, no Canadá e na Dinamarca, estabelecendo um paralelo com a formação brasileira na área. A idéia central do trabalho é refletir sobre as mudanças que estão ocorrendo na formação brasileira em Biblioteconomia/Ciência da Informação a partir das experiências dos três países mencionados.
\end{abstract}

Palavras-chave: formação profissional, Ciência da Informação, Biblioteconomia, Brasil, França, Canadá, Dinamarca

\begin{abstract}
Presents the system of education in Information Science in France, Canada and Denmark, establishing a parallel with the Brazilian system. The article intends to reflect on the changes that are occurring in the Brazilian education from the experiences of the three mentioned countries.
\end{abstract}

Key-words: Librarianship Education, Information Science, Library Science, Brazil, France, Canada, Denmark

\section{CONSIDERAÇÕES PRELIMINARES}

Este trabalho tem como objetivo estabelecer uma comparação entre cursos de Ciência da Informação da França, do Canadá e da Dinamarca com a formação brasileira nesta área. A seleção destes países se deu por vários motivos. Escolhemos a França em primeiro lugar, porque este país foi objeto de nossa pesquisa de doutorado que comparou o mercado de trabalho do profissional da informação francês e brasileiro. As Escolas da Biblioteconomia e Ciência da Informação de Montréal, no Canadá e a Royal School of Librarianship and Information Science da Dinamarca foram escolhidas porque ambas passaram recentemente por reformulações profundas com o objetivo de se adaptarem às mudanças do mercado de trabalho. A escola dinamarquesa é uma das maiores do mundo na área e vem se internacionalizando através de convênios formados com vários países e com programas da Comunidade Européia.

Embora a realidade destes países seja diferente do nosso, acreditamos que este estudo comparativo nos permitirá trazer subsídios para refletir sobre as mudanças de nossos programas de graduação.

Nos últimos 20 anos as profissões da informação conheceram transformações profundas aceleradas pela globalização da economia e pelo desenvolvimento das novas tecnologias.

Estas mudanças tecnológicas e estruturais da sociedade estão obrigando os profissionais da informação a redefinirem seu lugar no mercado de trabalho. Ao mesmo tempo que as funções

\footnotetext{
${ }^{1}$ Trabalho apresentado no VII Encontro das Escolas de Biblioteconomia da Região Sul, realizado em Rio Grande de 24 a 26 de junho de 1999.
}

Enc. Bibli: R. Eletr. Bibliotecon. Ci. Inf., ISSN 1518-2924, Florianópolis, Brasil, n.8, p.20-27, 1999. 
informacionais se tornam mais complexas e específicas esta tendência à especificidade não resultou no fortalecimento das profisssões clássicas da informação - mas, ao contrário, abriu possibilidades para especialistas de outras disciplinas. Estas mudanças estão nos levando a refletir sobre a adequação da formação que estamos dispensando atualmente aos profissionais da informação. A partir daí surgem algumas questões:

- que profissionais queremos formar?

- que papéis vão desempenhar?

- queremos formar generalistas que conheçam todos os aspectos do trabalho informacional?

- ou especialistas em alguns setores de atividade bem definidos?

- que setores são estes?

As novas possibilidades ofertadas pela LDB - Lei de Diretrizes e Bases, embora questionáveis em alguns aspectos, chegam num momento oportuno. A grande maioria das escolas brasileiras de Biblioteconomia e Ciência da Informação encontra-se atualmente num processo de reformulação curricular.

Este trabalho pretende contribuir para a reflexão sobre o assunto através de uma panorâmica da educação em Biblioteconomia/Ciência da Informação nos três países mencionados: França, Canadá e Dinamarca.

\section{FRANÇA}

O sistema de formação francês em Ciência da Informação se caracteriza por sua extrema diversidade, tanto no que se refere aos objetivos quanto aos níveis de formação e aos conteúdos. Essa diversidade tem vantagens e inconvenientes. Entre as vantagens podemos destacar a riqueza das possibilidades de escolha e o sistema de educação continuada que garante a todo profissional o direito de atualização periódica. Entre os inconvenientes podemos citar a falta de uma planificação global do ensino e a falta de relação entre as diferentes formações, o que dificulta o desenvolvimento de uma carreira profissional.

A distinção entre as carreiras e a formação de bibliotecários e documentalistas é uma especificidade francesa. A partir dos anos 60, existiram tentativas de criação de um tronco comum relativo às profissões de informação - biblioteconomia, documentação e arquivística - sem resultados concretos (Meyriat, 1993). Atualmente, embora existam algumas formações conjuntas de bibliotecários-documentalistas, no geral, as duas profissões desenvolvem cada uma seu próprio sistema de ensino.

Existem, na França, formações profissionais em Ciência da Informação em diversos níveis: o nível conhecido como primeiro ciclo corresponde a um curso de formação de técnico superior de duração de dois anos; o de segundo ciclo (com cursos que correspondem aos níveis brasileiros de graduação e de mestrado) e o de terceiro ciclo (com uma opção profissional e uma opção de pesquisa que leva ao doutorado). Todas as formações, com exceção do DEA (Diplôme d'Etudes Approfondies) ${ }^{2}$ tem, além da teoria, uma parte prática com períodos de estágio que variam de 2 a 6 meses.

Os cursos se realizam nas universidades e em escolas profissionais.

As instituições de formação de bibliotecários são a Ecole de Bibliothécaires et Documentalistes do Institut Catholique de Paris, o Institut de Formation des Bibliothécaires, também localizado em Paris e a ENSSIB-Ecole Nationale Supérieure de Sciences de l'Information et des Bibliothèques, em Lyon.

\footnotetext{
${ }^{2}$ O DEA corresponde ao primeiro ano de Doutorado. No final do DEA o aluno deve apresentar um trabalho de conclusão que o habilita a realizar a tese.
}

Enc. Bibli: R. Eletr. Bibliotecon. Ci. Inf., ISSN 1518-2924, Florianópolis, Brasil, n.8, p.20-27, 1999. 
A Ecole de Bibliothécaires et Documentalistes do Institut Catholique de Paris é uma escola privada de ensino superior. Foi fundada em 1935 como a primeira escola profissional francesa da área. O Institut de Formation des Bibliothécaires, um serviço da Direction du Livre et de la Lecture, do Ministério da Educação, organiza a formação inicial (básica) dos bibliotecários. A ENSSIB, criada em 1992, é a escola mais importante de formação destes profissionais. Ela se origina da transformação da Ecole Nationale Supérieure de Bibliothécaires criada em 1963.

O primeiro curso técnico de documentalistas, com duração de dois anos, se realizou em Paris, em 1945. Em 1950, esse curso é incorporado ao CNAM - Conservatoire National des Arts et Métiers sob o nome de INTD - Institut National des Techniques Documentaires. Com mais de 4000 profissionais formados e reconhecidos em todos os setores da administração pública, da indústria, do comércio e da educação, esse instituto ocupa um lugar de destaque no ensino de Ciência da Informação na França.

O curso do INTD de nível de segundo ciclo (equivalente ao mestrado) visa formar profissionais de informação-documentação capazes de desenvolver projetos, conservar e administrar um centro de documentação ou de informação, elaborar produtos de informação, criar serviços e conceber sistemas de informação. Este curso tem dois módulos de ensino:

1) características e tratamento da informação

2) planejamento e gestão de sistemas de informação.

O estágio deste curso tem uma duração de 3 meses e se desenvolve em dois períodos: a primeira parte é desenvolvida no meio do período de formação e tem o objetivo de observar e participar em atividades de informação da instituição escolhida; a segunda fase dura dois meses e se destina a cumprir uma tarefa que será objeto do trabalho de final do curso. Esta tarefa é, em geral, um projeto encomendado pela instituição onde o estágio está sendo desenvolvido.

A Ecole Nationale de Chartes, estabelecimento de educação superior, fundado em 1821 forma os conservateurs du patrimoine e os arquivistas-paleógrafos. A Direction des Archives de France realiza cursos de formação continuada para arquivistas.

O sistema de formação francês é construído de forma que o estudante faça sua escolha profissional o mais tarde possível. Isso significa que ele cursa, na maior parte dos casos, uma formação geral para depois optar por um curso profissionalizante. Esta formação geral inicial é considerada como uma vantagem para a adaptação e a evolução profissional, o que não acontece no sistema brasileiro. Uma outra característica deste sistema é a ausência de equivalência entre os diplomas profissionais e universitários. Essa situação impede a passagem de um ciclo de formação a outro. Além disso, apesar da diversificação com relação à duração dos estudos e ao grau de profissionalização de cada escola, os conteúdos de formação têm uma certa homogeneidade (exceção feita a alguns cursos de DESS - Diploma de Estudos Superiores Especializados) porque na realidade eles se caracterizam pela importância que dão à pratica profissional. Nesse sentido o saber fazer (savoir-faire) tem mais peso do que o saber. Não existe uma diferenciação nítida entre as diferentes formações ou entre as formações generalistas e as formações profissionalizantes.

Essa situação tem como consequência que estudantes de diferentes níveis de formação concorrem aos mesmos empregos. Os empregadores não têm uma idéia clara das habilidades adquiridas em cada curso e não conseguem estabelecer uma distinção entre a imensa variedade de formações existentes (Soenen, 1990, p.90). Essa realidade leva a situações onde o profíssional, no momento de seu recrutamento é considerado mais pelo seu nível de estudo do que pelo conteúdo de sua formação. Ela é uma consequência direta da ausência de uma carreira profissional definida.

\footnotetext{
3 “Os conservateurs du patrimoine exercem responsabilidades científicas e técnicas com a finalidade de estudar, classificar, manter, enriquecer, valorizar e dar a conhecer o patrimônio cultural (Cacaly, 1997, p.157). São, na realidade, funções próximas dos museólogos.
}

Enc. Bibli: R. Eletr. Bibliotecon. Ci. Inf., ISSN 1518-2924, Florianópolis, Brasil, n.8, p.20-27, 1999. 
Além disso, as mudanças sucessivas do sistema de ensino e a criação de novas formações se realizam com poucas discussões em nível profissional e acadêmico. Dessa forma, profissionais e professores se encontram muitas vezes diante de situações sem saída onde não é possível reagir.

A oferta de cursos na França está desequilibrada: um maior número de estudantes fazem cursos técnicos, enquanto os empregadores exigem níveis de qualificação mais elevados. Um outro problema é que apenas um número reduzido de estudantes escolhe a via da pesquisa o que a curto prazo poderá ocasionar uma falta de professores-pesquisadores.

A obrigação que os empregadores tem na França de oferecer uma formação continuada a seus empregados, a importância que as escolas, as associações e as empresas privadas dão a este tipo de formação estimulam a atualização profissional. Uma lei do governo francês de 1966 institucionaliza a formação continuada como uma obrigação nacional.

\section{DINAMARCA}

A educação bibliotecária na Dinamarca é realizada por uma única instituição de ensino, a Royal School of Librarianhsip and Information Science que funciona em Copenhagen e em Aalborg. Ela oferece como opções de formação a graduação em Biblioteconomia e Ciência da Informação, um mestrado em Ciência da Informação, um em cultura e mediação e programas de educação continuada. Antes de 1989 não havia qualificação formal em Biblioteconomia e Ciência da Informação neste país. Entretanto, desde 1956 a Royal School vinha formando bibliotecários para atender seu mercado de trabalho.

Esta escola encontra-se atualmente num processo de reestruturação de forma a adequar seus programas às tendências internacionais e tornar-se mais visível no mercado.

O curso de graduação é ofertado em 8 semestres, com ênfase nos aspectos teóricos, metodológicos e instrumentais. O primeiro semestre aborda o tema Cultura e informação na sociedade; o segundo é denominado Curso básico de biblioteconomia e abrange os aspectos introdutórios e fundamentais. $\mathrm{O}$ terceiro semestre é destinado à prática em uma biblioteca pública, universitária ou empresarial. O quarto semestre abrange o conteúdo de Seleção de documentos e mediação.

No quinto e sexto semestres os estudantes tem que cursar disciplinas de economia e administração e Interação entre usuários e sistemas de informação. As disciplinas optativas levam os estudantes a se especializarem em um tipo de bibliotecas e unidades de informação.

Durante o sétimo semestre o estudante deve optar por dois seminários de um conjunto que enfoca temas como debates culturais atuais, cultura americana, Internet, marketing e busca eletrônica de informação, entre outros. No oitavo semestre o estudante elabora uma monografia.

O mestrado em Ciência da Informação que existe desde 1990, tem como objetivo preparar pessoal com habilidades e competências em: estudo de necessidades de informação, implementação de estruturas de informação, gestão da informação, tecnologia da informação, elementos psicológicos e linguísticos de busca da informação, implementação, design e gestão de sistemas de informação e pesquisa avançada da informação. $O$ curso tem a duração de quatro semestres em tempo integral ou oito semestres em tempo parcial. O último semestre é dedicado à redação da dissertação.

O programa de pós-graduação em Mediação e cultura prepara alunos para áreas como trabalho cultural, educação de adultos e mediação em instituições.

A Royal School of Information Science oferece ainda programas de educação continuada para bibliotecários, assistentes de biblioteca e outros profissionais que atuam no campo da informação.

A partir de 1994 a Escola começou a se internacionalizar e firmou convênios de cooperação com a Inglaterra, Holanda, Hungria, Alemanha, Suécia, Finlândia, Rússia, Ucrânia e Austria. Participa ainda ativamente do programa de intercâmbio e cooperação de educação superior da 
Comunidade Européia - Erasmus/Socrates com outros países europeus. Esta instituição oferece anualmente no âmbito deste programa um curso anual de 11 semanas com conferencistas da Inglaterra, Irlanda, Grécia e Alemanha. O programa enfatiza conteúdos relativos às tecnologias da informação e ao acesso à informação.

\section{CANADÁ}

O sistema educational do Canadá é bastante semelhante ao americano. As escolas profissionais canadenses da área de Ciência da Informação são reconhecidas pela ALA - American Library Association.

A "Ecole de Bibliothéconomie et des Sciences de l'Information" (EBSI) é uma escola profissional. Fundada em 1937 foi reestruturada em 1961 quando se integra à Universidade de Montréal com o nome de Escola de Biblioteconomia com um curso de nível de bacharelado que tinha a duração de um ano de 1961 a 1966 e de dois anos de 1966 a 1971.

De 1971 a 1984 a Escola possuia um mestrado em Biblioteconomia. Em 1984 este mestrado passou a chamar-se de Biblioteconomia e Ciência da Informação quando a escola passou a chamarse Escola de Biblioteconomia e Ciência da Informação.

Esta escola tem sido reestruturada periodicamente. Uma pesquisa feita por Tabah \& Bernhard (1998), encomendada no âmbito da reformulação dos programas dos cursos, realizou uma ampla consulta envolvendo alunos, professores, profissionais da área e empregadores. A última revisão do seu programa, realizada em 1998, resultante desta consulta à comunidade responde a uma diversificação evidenciada no mercado. Os novos perfis definidos para o curso de mestrado são:

- Desenvolvimento e gestão de fundos documentais

- Criação e gestão de catálogos

- Análise da informação e bases de dados

- Difusão da informação

- Gestão de serviços e de recursos informacionais

- Informática documentária e tecnologias de informação

- Bibliotecas públicas

- Ambiente escolar

- Perfil individualizado

A distribuição dos conteúdos é feita da seguinte forma: no primeiro ano são ministradas as disciplinas obrigatórias (em número de 8 ); no $2^{\circ}$ ano o aluno opta por uma especialização e realiza um estágio. As disciplinas de pesquisa representam cerca de $20 \%$ do conteúdo programático.

Segundo Landa (1994) a escola tem se adaptado bem às mudanças do mercado. Entretanto as últimas alterações dos programas ainda não foram suficientemente absorvidas para mostrar resultados porque são muito recentes.

Esta escola oferece igualmente a partir de 1983 um diploma de arquivística de nível de graduação e a partir de 1997, um programa de doutorado em Ciência da Informação.

\section{COMPARAÇÃO E CONCLUSÕES}

Mesmo com programas de ensino baseados em pesquisas de mercado e preoucupados em responder às mudanças da sociedade da informação como os que vem sendo desenvolvidos na França, Dinamarca e Canadá, é possível verificar a dificuldade dos programas de acompanhar o ritmo imposto por tais transformações. Para minimizar o descompasso entre a formação e as exigências do mercado as escolas destes países investem massivamente em formação continuada.

Enc. Bibli: R. Eletr. Bibliotecon. Ci. Inf., ISSN 1518-2924, Florianópolis, Brasil, n.8, p.20-27, 1999. 24 
As instituições francesas, dinamarquesas e canadenses permitem aos profissionais atuantes no mercado realizar cursos regulares dentro de programas especialmente concebidos para tal. A formação contínuada destes três países se diferencia da brasileira na medida em que se realiza a qualquer nível profissional. No Brasil, ao contrário, a maioria dos cursos deste tipo exige um nível de formação superior. Os cursos de formação de técnicos e auxiliares são raros.

A formação profissional no Brasil e na França se ressente da falta de uma política específica que possa estabelecer as grandes linhas em matéria de educação em Ciência da Informação e identificar suas necessidades. A falta de ligação entre os vários níveis, a falta de uma visão de conjunto, a ausência de um equilíbrio entre os diferentes tipos de formação, características comuns aos dois países, são consequência da ausência desta política. Para ser eficaz essa política deve apoiar-se na realidade do mercado. Assim será possível orientar de forma integrada e sistemática o desenvolvimento das formações, a criação de novos cursos e a coerência do sistema educacional da área como um todo.

Ao contrário dos programas franceses e brasileiros que se caracterizam pela falta de continuidade, o programa dinamarquês oferece uma carreira profissional que compreende 4 anos de graduação mais dois anos de mestrado profissional.

$\mathrm{Na}$ França, as formações de primeiro ciclo (técnicas) representam a maioria dos formandos; no Brasil, os estudantes de graduação são maioria. Mas, nos dois países existe uma demanda por profissionais como uma formação mais elevada e mais especializada. (Meyriat, 1993, p.98, Vieira, 1990, p.172). A criação de novas formações exige que as necessidades e a evolução do mercado sejam avaliadas e previstas de forma precisa. Na realidade, os dois países se caracterizam por uma falta de estudos regulares de mercado de forma que seja possível conhecer as necessidades de profissionais de informação.

A formação francesa em Ciência da Informação é sempre de curta duração (de 12 a 18 meses). Não existe neste país uma hierarquia de progressão de conhecimentos. Na Dinamarca, ao contrário, como em outros países europeus, o sistema de ensino na área se insere numa perspectiva de carreira profissional planejada com progressão dentro dos diferentes níveis.

A educação brasileira se caracterizou até o momento por uma uniformidade de conteúdos de cursos de graduação em função das exigências do currículo mínimo; os sistemas francês e dinamarquês se caracterizam pela diversidade de seus conteúdos e de seus níveis de formação. Na França e no Canadá a dupla formação (em Biblioteconomia/Documentação/Ciência da Informação e em outra área do conhecimento) é bastante comum. Este tipo de formação é pouco desenvolvido no Brasil e não é reconhecido oficialmente porque os conselhos de Biblioteconomia recusam o acesso à profissão a profissionais de informação que possuam uma graduação em outros campos do conhecimento.

No Brasil e na França a criação de um tronco comum para as profissões da informação (Biblioteconomia, Arquivística e Documentação) preconizada pela Unesco foi discutida sem levar a resultados concretos (Meyriat, 1993; Miranda, 1989).

Os estágios ocupam uma parte importante na prática profissional em todos os países estudados como acontece no Brasil.

Os cursos destinados em princípio à pesquisa como o DEA francês e o mestrado brasileiro são frequentados por profissionais que procuram, nestes dois países através dessas formações, um melhor status profissional. Neste sentido o objetivo desses cursos que é, em princípio, a pesquisa, é deturpado. Essa situação é consequência, nos dois países, da falta de uma definição clara dos objetivos deste tipo de formação.

França e Dinamarca participam, em nível da Comunidade Européia, de discussões no sentido de uma harmonização, de uma cooperação mais estreita e de um reconhecimento dos diplomas em Ciência da Informação. A especificidade da formação profissional francesa é um fator complicador na integração daquele país aos sistemas europeus (Prevot, 1997). O Brasil tem participado, de discussões neste sentido, junto com os países integrantes do Mercosul. A 
semelhança relativa dos sistemas de formação latino-americanos facilita o intercâmbio entre estes países. As escolas do Canadá são reconhecidas pela American Library Association, o que garante uma compatibilidade de programas em nível da região.

Partindo de uma das características gerais das formações francesa e canadense que é a dupla formação - podemos afirmar que o profissional destes países têm uma bagagem cultural sólida que lhe permite uma reflexão mais profunda sobre os problemas do dia a dia, a tomada de decisões e o diálogo com profissionais de outras áreas. Entretanto, na França, o número reduzido de horas de ensino profissional não the permite um aprofundamento técnico. No Brasil, ao contrário, a formação em nível de graduação talvez seja longa demais e muito centrada na técnica. Na nossa opinião falta ao bibliotecário brasileiro esta bagagem cultural que lhe permitiria lidar melhor com os problemas da profissão.

É possível observar ainda que mesmo com programas mais "avançados" (se podemos utilizar esta expressão), os profissionais formados nas escolas do Canadá, da França, e da Dinamarca, estão sendo recrutados pelo mercado tradicional, mas tem ainda pouca visibilidade nos novos espaços informacionais que estão se abrindo e ainda são minoria frente a outras profisssões.

As transformações são muito rápidas. É impossível a qualquer escola, mesmo com reformulações periódicas e constantes dos seus programas, estar em dia e em sintonia com o mercado de trabalho.

As mudanças da tecnologia e a globalização dos mercados estão levando as profíssões a repensar a natureza do profissionalismo. Formar profissionais integrados na realidade e que possam responder às necessidades atuais e futuras para novos mercados de trabalho, bem como para os mercados tradicionais, é um verdadeiro desafio.

\section{BIBLIOGRAFIA}

ADBS. La certification des professionnels de l'information et de la documentation. Paris: ADBS, 1994. 4p.

ADBS. Les formations. http://www.adbs.fr 1998.

BLANQUET, Marie-France. L'enseignement théorique peut-il être nuisible? DocumentalisteSciences de l'Information, Paris, v.26, n.3, p.125-131, mar-.juin.1989.

DELMAS, Bruno. L'INTD et son rôle dans la formation des documentalistes en France. Documentaliste-Sciences de l'Information, Paris, v.30, n.4/5, p.218-226, juil.-oct.1993.

L'ECOLE DE BIBLIOTHÉCONOMIE ET DES SCIENCES DE L'INFORMATION. Présentation de l'EBSI. http://www.faz.unmontreal.ca/ebsi Mai 1999.

LAHARY, Dominique. Conservateur de bibliothèque. In: CACALY, Serge et all. Dictionnaire encyclopédique de l'information et de la documentation. Paris: Nathan, 1997. p.157

LANDA, Éveline. Qu'em est-il de l'enseignement de la bibliothéconomie et des Sciences de l'Information au Québec? Argus, Montréal, v.23, n.2, p.9-12, mai-août 1994.

MACFARLANE, Judy, TEES, Miriam. Special library education and continuing education in Canada. Library Trends, Chicago, v..42, n.2, p.304-318, Fall 1993.

MEIRYAT, J. La formation initiale em France, des professionnels de l'information et des bibliothèques. Documentaliste-Sciences de l'Information, Paris, v.30, n.2, p.91-98, mars/avril 1993.

MIRANDA, A. The role of professionalism in curriculum development for information personnel: the case of Brazil. In: Proceedings of na International Colloquium on the Harmonization of Education and Training Programmes for Library and Information and Archival Personnel. Munchen: K.G.Saur, 1989, p.236-249. 
PIÑON, F. O estado da arte e as tendências da formação do profissional de informação latinoamericano. Revista de Biblioteconomia da UFMG, Belo Horizonte, v.22, n.1, p.66-88, jan./jun.1993.

PORS, Niels Ole, KAJBERG, Leif. Royal School of Information Science: present educational programmes and envisaged curricular changes. http://www.db.dk August 1998.

PREVOT-HUBERT, M. Penser les necéssaires mutations des formations. Documentaliste-Sciences de l'Information, Paris, v.34, n.2, p.101-103, mars-avril 1997.

SAVARD, Réjean. À la croisée des chemins: l'évolution de la profession de bibliothécaire. Argus, Montréal, v.21, n.1, p.9-14, Printemps-été 1992.

SOENEN, H. La représentation des métiers des bibliothèques et de la documentation à travers les offres d'emploi et les programmes de formation. Cahiers de la Documentation, Grenoble, n.6, p.67-115, juin 1990.

TABAH, Albert N. Emplois occupés après la diplômation et champs d'activité perçus comme importants "aujourd-hui" et "dans cinq ans" selon l'enquête menée auprès des diplômés de l’EBSI (1991-1995). Argus, Montréal, v.27, n.2, p.5-13, Automne 1998.

VIEIRA, A.S., CAMPELLO, B.S., PAIM, I. Nova alternativa em educação dos profissionais da informação: o curso de GRI na EB/UFMG. Revista da Escola de Biblioteconomia da UFMG, Belo Horizonte, v.19, n.2, p.171-181, set.1990. 